Article

\title{
Breast Cancer Screening Behaviors in Women Aged 40 Years and Over in a Semi-Urban Region in Turkey: Relationships with Health Beliefs
}

\author{
Kevser Tarı Selçuk ${ }^{1, *}$, Dilek Avcı ${ }^{2}$, Gönül Yılmaz Dündar ${ }^{2}$ and Yeliz Mercan ${ }^{3}$ \\ 1 Department of Nutrition and Dietetics, Faculty of Health Sciences, Bandırma Onyedi Eylül University, \\ Bandırma, 10200 Balıkesir, Turkey \\ 2 Nursing Department, Faculty of Health Sciences, Bandırma Onyedi Eylül University, Bandırma, \\ 10200 Balıkesir, Turkey; davci@bandirma.edu.tr (D.A.); gyilmaz@bandirma.edu.tr (G.Y.D.) \\ 3 Department of Health Management, Kırklareli University School of Health, 39000 Kırklareli, Turkey; \\ yelizmercan@klu.edu.tr \\ * Correspondence: kselcuk@bandirma.edu.tr
}

Received: 15 May 2020; Accepted: 11 June 2020; Published: 13 June 2020

\begin{abstract}
In this study, we aimed to determine the breast cancer screening behavior of women and to investigate the relationship between health beliefs and screening behaviors. The study was cross-sectional. It was conducted between April 2017 and June 2017 with 416 women aged $\geq 40$. The Sociodemographic Information Form and the Champion's Health Belief Model Scale were used to collect data. In the statistical analysis, the number, percentage, mean, standard deviation, Pearson chi-square test, and multivariate binary logistic regression analysis were used. The rates for participating women performing breast self-examination, having clinical breast examination, and undergoing mammography were $11.8 \%, 8.9 \%$, and $11.3 \%$, respectively. Perceived susceptibility, seriousness, self-efficacy, benefits, health motivation, and perceived barriers were found to have strong associations with screening behaviors $(p<0.05)$. In this study, we found that few women performed breast self-examination, had clinical breast examination and mammography. In the present study, women perceived barriers related to both performing breast self-examination and undergoing mammography.
\end{abstract}

Keywords: breast cancer; breast self-examination; mammography

\section{Introduction}

Breast cancer $(\mathrm{BC})$ is one of the most common types of cancer in women globally and accounts for a quarter of all new cancer cases, ranking second in cancer-related deaths across the world [1]. $\mathrm{BC}$ is the most fatal and most common type of cancer in women in Turkey, with an incidence of 47 per 100,000 [2].

The early diagnosis of $\mathrm{BC}$ is critical to reducing mortality. The literature shows that BC mortality rates have increased by about $14 \%$ since 2008 and that this increase is higher in developing countries due to delay in diagnosis and inadequate treatment $[3,4]$. In Turkey, in order to diagnose BC early and to decrease the BC-related mortality rate in women, the BC screening program has been carried out [5]. Within the scope of this program, the intention is to screen women in the 40-69 age group through mammography every two years; however, due to the shortage of specialized staff, problems with access to health service, and lack of awareness, the screening program currently covers only 20-30\% of the target population in Turkey, and the majority of BC's are diagnosed during the advanced stage [2]. In Turkey, the main screening method for early diagnosis of BC is mammography. The Ministry of Health recommends that women should undergo a mammography every two years from the age 
of 40 , that clinical breast examination (CBE) should be performed in every woman participating in the screening in order to increase the effectiveness of mammography [5] and that the CBE should be repeated once a year [6]. Breast self-examination (BSE), which is still used as a screening method in developing countries, is not recommended by the World Health Organization (WHO) as a screening method, but is considered as an intervention that raises awareness among women at risk $[7,8]$. In randomized controlled studies performed recently, it has been shown that BSE is not an effective method for reducing cancer-related mortality [4]. However, in some other studies, it is stated that BSE may have contributed to the reduction of BC mortality by increasing women's awareness of BC in some countries [9] and it is reported that BSE should be encouraged not as a method to reduce mortality but as a part of awareness-raising programs [9]. In Turkey, the Ministry of Health recommends that after the age of 20, every woman should perform BSE every month to raise their awareness of BC $[5,6]$. The low implementation rates of BSE (8.9-49.4\%), of CBE (18.0-35.8\%), and mammography $(19.7-37.9 \%)$ in different regions of Turkey also reveal that to ensure positive change in BC screening behaviors, appropriate interventions should be planned as soon as possible [10-15].

Several factors may affect the performance of BC screening behaviors [16-20]. In the literature, it states that, in addition to sociodemographic and cultural characteristics, health beliefs related to the disease and its consequences affect health behaviors by increasing the motivation of individuals [21]. The Champion's Health Belief Model is one of the models widely used to convey beliefs that can be effective in shaping health protection and health promotion behaviors $[16,19,21]$. In this model, women are encouraged to have BC screening tests to: find out whether they are at an increased risk of BC (perceived susceptibility); how severe the risk is considering its physical, mental, and social aspects (perceived severity); understand that early diagnosis would reduce negative health consequences (perceived benefits); understand that screening behavior is not costly, and that the person herself can perform the behavior (self-efficacy) [22]. Birhane et al. studied the rate of performing BSE, and found that it was high in women whose susceptibility and BSE benefit perception were high [23]; in the study by Eltvansy, the rate of having CBE was found to be high in women whose susceptibility, seriousness, and health motivation were high [24], and in the study by Shiryazdi et al., the rate of undergoing mammography was found to be high in women whose seriousness and mammography benefit perception were high [25]. In Turkey, studies investigated the BC screening behavior and health beliefs, although these studies mostly focused on one or two of the BC screening behaviors and were conducted with women of younger age $[12,15,26,27]$. In the recent studies conducted in Turkey, the rate of performing BSE was high in those whose perceptions of seriousness [15], self-efficacy [15,26,27], benefits [26,27], and motivation were high [26], and the rates of performing BSE [15,27] and undergoing mammography were high in those whose perception of barriers is low [15]. Investigating the three screening behaviors together in women aged 40 and older living in semi-urban areas to reveal the relationships between these behaviors and health beliefs will contribute to the determination of strategies that aim to increase $\mathrm{BC}$ screening behaviors in the region and to the planning of interventions.

This study aimed to determine women's BC screening behaviors and to investigate the relationship between health beliefs and screening behaviors.

\section{Materials and Methods}

\subsection{Study Type and Sample}

This was a cross-sectional study. It was conducted in a semi-urban region of Bandirma, which is a district of the Balıkesir province, located on the coast of the Marmara Sea in the western part of Turkey.

To determine sample size, electronic databases were searched using keywords to access national studies on BC screening behaviors. In a recent national study, the rate of mammography was reported to be $19.0 \%$ in women (aged $\geq 30$ ) [14]. The minimum sample was calculated to be 355 by taking $p=0.19, \alpha=0.05$, and $d=0.03$, using the Epi Info 7.2 program [28]. It was then decided to include $20 \%$ more people as substitutes and as a result, the target was to reach 426 women. The inclusion 
criteria were women who presented to the family health center $(\mathrm{FHC})$ for any reason $(n=811)$ between 3 April 2017 and 28 June 2017 when the unit was not in mobile service, who had cognitively capable of answering the research questions $(n=808)$, and volunteered to participate in the study $(n=682)$. The exclusion criteria were then applied to the participants $(n=682)$, which was those who were under 40 years of age $(n=228)$, who were pregnant $(n=24)$, and who had a history of BC $(n=14)$, resulting in 416 women whose data were analyzed.

\subsection{Data Collection Tools}

Data were collected by using the Sociodemographic Information Form and the Champion's Health Belief Model Scale. The Champion's Health Belief Model Scale was developed by Champion, and the validity and reliability study of the Turkish version of the scale was conducted by Gözüm. The five-point Likert-type scale consisted of 52 items and 8 subscales: susceptibility, seriousness, health motivation, BSE benefits, BSE barriers, BSE self-efficacy, mammography benefits, and mammography barriers. Internal consistency coefficients for the subscales were reported to range between 0.69 and 0.83 [21,29]. In this study, the Cronbach alfa coefficients of the subscales were calculated as $0.84-0.96$.

\subsection{Ethical Approval}

Before data collection, ethics approval was received from the Balıkesir University Clinical Research Ethics Committee (Decision date and no: 2017/27). In this study, we followed the principles outlined in the Declaration of Helsinki for Human Studies.

\subsection{Statistical Analysis}

The descriptive characteristics and BC screening behaviors of the participants were given in numbers and percentages. Pearson's chi-square test was used to compare the screening behaviors of women in terms of their sociodemographic characteristics. Mean, standard deviation, and minimum and maximum values related to the subscale scores of the Champion's Health Belief Model Scale were given. The relationship between health beliefs and BC screening behaviors was analyzed using the multivariate binary logistic regression analysis. For each regression model, BC screening behaviors were the dependent variables, and the subscales of the Champion's Health belief Model scale were the primary independent variable, with age, education level, perceived economic status, and family history of BC added to the model as covariates. The Hosmer-Lemeshow goodness-of-fit test was used to determine how well the model fits with the data. The explanation of the model was evaluated with the Nagelkerke R square. All analyses were performed with SPSS Statistics for Windows version 23.0 (SPSS Inc., Chicago, IL, USA) and $p<0.05$ was used to assess for significance.

\section{Results}

The sociodemographic characteristics of the participants are presented in Table 1.

Table 1. Sociodemographic characteristics of the participants $(n=416)$.

\begin{tabular}{ccc}
\hline Sociodemographic Characteristics & $\boldsymbol{n}$ & $\mathbf{\%}$ \\
\hline Age & & \\
$40-49$ & 157 & 37.7 \\
$50-59$ & 119 & 28.6 \\
$\geq 60$ & 140 & 33.7 \\
\hline Marital status & & \\
Married & 333 & 80.0 \\
Single/divorced/widow & 83 & 20.0 \\
\hline
\end{tabular}


Table 1. Cont

\begin{tabular}{ccc}
\hline Sociodemographic Characteristics & $\boldsymbol{n}$ & $\mathbf{\%}$ \\
\hline Education level & & \\
Primary school or lower & 225 & 54.1 \\
Secondary school & 158 & 38.0 \\
High school and higher & 33 & 7.9 \\
\hline Employment status & & \\
Yes & 46 & 11.1 \\
No & 370 & 88.9 \\
\hline Perceived economic status & & \\
Good & 52 & 12.5 \\
Moderate & 305 & 73.3 \\
Bad & 59 & 14.2 \\
\hline Health insurance & & \\
Yes & 403 & 96.9 \\
No & 13 & 3.1 \\
\hline Family history & & \\
Yes & 54 & 13.0 \\
No & 362 & 87.0 \\
\hline
\end{tabular}

The rates for women having performed BSE in the last month, having had CBE in the last year, and having undergone mammography in the last two years were $11.8 \%, 8.9 \%$, and 11.3\%, respectively (Table 2).

Table 2. Breast cancer screening behaviors of the participants $(n=416)$.

\begin{tabular}{ccc}
\hline Screening Behaviors & $n$ & $\%$ \\
\hline Breast self-examination (BSE) $^{*}$ & & \\
Yes & 49 & 11.8 \\
No & 367 & 88.2 \\
\hline Clinical breast examination (CBE) $^{* *}$ & & \\
Yes & 37 & 8.9 \\
No & 379 & 91.1 \\
\hline Mammography *** & & \\
Yes & 47 & 11.3 \\
No & 369 & 88.7 \\
\hline
\end{tabular}

* In the last month. ${ }^{* *}$ In the last year. ${ }^{* * *}$ In the last two years.

There was a statistically significant association between the BC screening behaviors and some sociodemographic characteristics (Table $3, p<0.05$ ).

Table 3. Breast cancer screening behaviors in the participants according to sociodemographic characteristics.

\begin{tabular}{|c|c|c|c|c|c|c|c|c|c|}
\hline \multirow{3}{*}{$\begin{array}{l}\text { Sociodemographic } \\
\text { Characteristics }\end{array}$} & \multicolumn{3}{|c|}{ BSE } & \multicolumn{3}{|c|}{ CBE } & \multicolumn{3}{|c|}{ Mammography } \\
\hline & Yes & No & \multirow{2}{*}{$p^{*}$} & Yes & No & \multirow{2}{*}{$p^{*}$} & Yes & No & \multirow{2}{*}{$p^{*}$} \\
\hline & $\%$ & $\%$ & & $\%$ & $\%$ & & $\%$ & $\%$ & \\
\hline \multicolumn{10}{|l|}{ Age } \\
\hline $40-49$ & 14.0 & 86.0 & 0.021 & 8.3 & 91.7 & 0.943 & 10.8 & 89.2 & 0.436 \\
\hline $50-59$ & 16.0 & 84.0 & & 9.2 & 90.8 & & 14.3 & 85.7 & \\
\hline$\geq 60$ & 5.7 & 94.3 & & 9.3 & 90.7 & & 9.3 & 90.7 & \\
\hline
\end{tabular}


Table 3. Cont

\begin{tabular}{|c|c|c|c|c|c|c|c|c|c|}
\hline \multirow{3}{*}{$\begin{array}{l}\text { Sociodemographic } \\
\text { Characteristics }\end{array}$} & \multicolumn{3}{|c|}{ BSE } & \multicolumn{3}{|c|}{ CBE } & \multicolumn{3}{|c|}{ Mammography } \\
\hline & Yes & No & \multirow{2}{*}{$p^{*}$} & Yes & No & \multirow{2}{*}{$p^{*}$} & Yes & No & \multirow{2}{*}{$p^{*}$} \\
\hline & $\%$ & $\%$ & & $\%$ & $\%$ & & $\%$ & $\%$ & \\
\hline \multicolumn{10}{|l|}{ Marital status } \\
\hline Married & 14.1 & 85.9 & 0.003 & 7.5 & 92.5 & 0.047 & 11.4 & 88.6 & 0.884 \\
\hline Single/divorced/widov & v 2.4 & 97.6 & & 14.5 & 85.5 & & 10.8 & 89.2 & \\
\hline \multicolumn{10}{|l|}{ Education level } \\
\hline $\begin{array}{c}\text { Primary school or } \\
\text { lower }\end{array}$ & 8.4 & 91.6 & 0.041 & 8.9 & 91.1 & 0.024 & 8.0 & 92.0 & 0.000 \\
\hline Secondary school & 14.6 & 85.4 & & 6.3 & 93.7 & & 10.1 & 89.9 & \\
\hline $\begin{array}{l}\text { High school and } \\
\text { higher }\end{array}$ & 21.2 & 78.8 & & 21.2 & 78.8 & & 39.4 & 60.6 & \\
\hline \multicolumn{10}{|l|}{ Employment status } \\
\hline Yes & 17.4 & 82.6 & 0.211 & 6.5 & 93.5 & 0.549 & 17.4 & 82.6 & 0.166 \\
\hline No & 11.1 & 88.9 & & 9.2 & 90.8 & & 10.5 & 89.5 & \\
\hline \multicolumn{10}{|l|}{$\begin{array}{c}\text { Perceived } \\
\text { economic status }\end{array}$} \\
\hline Good & 5.8 & 94.2 & 0.290 & 19.2 & 80.8 & 0.019 & 19.2 & 80.8 & 0.031 \\
\hline Moderate & 13.1 & 86.9 & & 7.2 & 92.8 & & 11.5 & 88.5 & \\
\hline Bad & 10.2 & 89.8 & & 8.5 & 91.5 & & 3.4 & 96.6 & \\
\hline \multicolumn{10}{|l|}{ Health insurance } \\
\hline Yes & 11.7 & 88.3 & 0.682 & 8.9 & 91.1 & 0.877 & 10.9 & 89.1 & 0.173 \\
\hline No & 15.4 & 84.6 & & 7.7 & 92.3 & & 23.1 & 76.9 & \\
\hline \multicolumn{10}{|l|}{$\begin{array}{c}\text { Family history of } \\
\text { BC }\end{array}$} \\
\hline Yes & 16.7 & 83.3 & 0.232 & 7.4 & 92.6 & 0.681 & 27.8 & 72.2 & 0.000 \\
\hline No & 11.0 & 89.0 & & 9.1 & 90.9 & & 8.8 & 91.2 & \\
\hline
\end{tabular}

The mean scores obtained from participants for subscales are presented in Table 4.

Table 4. Mean scores on the Health Belief Model Subscale.

\begin{tabular}{cccc}
\hline Health Belief Model Subscale & $\overline{\mathbf{X}}$ Standard Deviation (SD) & Min.-Max. & Score Range \\
\hline Susceptibility & $8.41 \pm 2.26$ & $3.00-15.00$ & $3.00-15.00$ \\
Seriousness & $20.34 \pm 5.01$ & $6.00-30.00$ & $6.00-30.00$ \\
Health motivation & $19.03 \pm 3.85$ & $5.00-25.00$ & $5.00-25.00$ \\
BSE benefits & $14.17 \pm 3.17$ & $4.00-20.00$ & $4.00-20.00$ \\
BSE barriers & $22.96 \pm 7.46$ & $8.00-37.00$ & $8.00-40.00$ \\
BSE self-efficacy & $30.33 \pm 9.39$ & $10.00-50.00$ & $10.00-50.00$ \\
Mammography benefits & $18.21 \pm 4.34$ & $5.00-25.00$ & $5.00-25.00$ \\
Mammography barriers & $33.99 \pm 10.66$ & $11.00-55.00$ & $11.00-55.00$ \\
\hline
\end{tabular}

According to the multivariate binary logistic regression analysis, the women who perceived more susceptibility, BSE self-efficacy, benefits of BSE, and fewer barriers to BSE were more likely to perform BSE. The women who perceived more seriousness and health motivation were more likely to have CBE. The women who perceived more seriousness, benefits of mammography, and fewer barriers to mammography were more likely to participate in mammography screening (Table $5, p<0.05$ ). 
Table 5. The relationship between the participants' health beliefs and screening behaviors according to multivariate binary logistic regression analysis.

\begin{tabular}{|c|c|c|c|c|c|c|}
\hline \multirow{2}{*}{ Variables } & \multicolumn{2}{|c|}{ BSE } & \multicolumn{2}{|c|}{ CBE } & \multicolumn{2}{|c|}{ Mammography } \\
\hline & UOR (\%95 CI) & AOR (\%95 CI) & UOR (\%95 CI) & AOR (\%95 CI) & UOR (\%95 CI) & AOR (\%95 CI) \\
\hline Susceptibility & $\begin{array}{c}1.27 \\
(1.14-1.41)^{* * *}\end{array}$ & $\begin{array}{c}2.02 \\
(1.02-3.99) *\end{array}$ & $\begin{array}{c}0.99 \\
(0.88-1.12)\end{array}$ & $\begin{array}{c}0.88 \\
(0.77-1.02)\end{array}$ & $\begin{array}{c}1.10 \\
(0.99-1.22)\end{array}$ & $\begin{array}{c}1.14 \\
(0.98-1.33)\end{array}$ \\
\hline Seriousness & $\begin{array}{c}1.51 \\
(1.33-1.71)^{* * *}\end{array}$ & $\begin{array}{c}1.39 \\
(0.93-2.07)\end{array}$ & $\begin{array}{c}1.12 \\
(1.04-1.20)^{* *}\end{array}$ & $\begin{array}{c}1.08 \\
(1.02-1.17)^{*}\end{array}$ & $\begin{array}{c}1.1 \\
(1.04-1.19)^{* *}\end{array}$ & $\begin{array}{c}1.15 \\
(1.07-1.24)^{* * *}\end{array}$ \\
\hline Health motivation & $\begin{array}{c}1.01 \\
(0.93-1.08)\end{array}$ & $\begin{array}{c}0.98 \\
(0.76-1.26)\end{array}$ & $\begin{array}{c}1.45 \\
(1.26-1.68)^{* * *}\end{array}$ & $\begin{array}{c}1.42 \\
(1.21-1.66)^{* * *}\end{array}$ & $\begin{array}{c}1.08 \\
(1.01-1.16)^{*}\end{array}$ & $\begin{array}{c}0.93 \\
(0.85-1.02)\end{array}$ \\
\hline BSE benefits & $\begin{array}{c}2.66 \\
(2.13-3.33) * * *\end{array}$ & $\begin{array}{c}2.43 \\
(1.37-4.29) * *\end{array}$ & NA & NA & NA & NA \\
\hline BSE barriers & $\begin{array}{c}0.65 \\
(0.58-0.73)^{* * *}\end{array}$ & $\begin{array}{c}0.67 \\
(0.53-0.84)^{* * *}\end{array}$ & NA & NA & NA & NA \\
\hline BSE self-efficacy & $\begin{array}{c}1.39 \\
(1.28-1.51)^{* * *}\end{array}$ & $\begin{array}{c}1.55 \\
(1.11-2.17) * *\end{array}$ & NA & NA & NA & NA \\
\hline $\begin{array}{l}\text { Mammography } \\
\text { benefits }\end{array}$ & NA & NA & NA & NA & $\begin{array}{c}1.22 \\
(1.12-1.33) * * *\end{array}$ & $\begin{array}{c}1.45 \\
(1.27-1.65)^{* * *}\end{array}$ \\
\hline $\begin{array}{l}\text { Mammography } \\
\text { barriers }\end{array}$ & NA & NA & NA & NA & $\begin{array}{c}0.95 \\
(0.92-0.98) * *\end{array}$ & $\begin{array}{c}0.90 \\
(0.87-0.94)^{* * *}\end{array}$ \\
\hline $\begin{array}{l}\text { UOR: Unadjust } \\
* * p<0.01, * * * \\
1 \text {, high school } \\
\text { yes: 1). BSE: H } \\
\text { and Lemeshov } \\
\text { Lemeshow test }\end{array}$ & $\begin{array}{l}\text { Odds Ratio. } \\
0.001 \text {. Odds } \\
\text { higher: 2), } \\
\text { her and Lem } \\
\text { st: chi squa } \\
\text { hi square }=2\end{array}$ & $\begin{array}{l}\text { Adjusted } \\
\text { adjusted for } \\
\text { ved econom } \\
v \text { test: chi sq } \\
3.360, p=0 \\
p=0.902, \mathrm{~N}\end{array}$ & $\begin{array}{l}\text { Ratio. CI: C } \\
\text { education le } \\
\text { tus (bad: } 0,1 \\
=0.844, p= \\
\text { Nagelkerke } \\
\text { erke R squa }\end{array}$ & $\begin{array}{l}\text { dence Interv } \\
\text { primary sch } \\
\text { lerate: } 1 \text {, goc } \\
8 \text {, Nagelkerl } \\
\text { quare }=0.24 \\
0.493 .\end{array}$ & $\begin{array}{l}\text { A: Not applic } \\
\text { r lower: } 0 \text {, sec } \\
\text {, family histo } \\
\text { quare }=0.941 \\
\text { ammography }\end{array}$ & $\begin{array}{l}\text { e. }{ }^{*} p<0.05 \text {, } \\
\text { dary school: } \\
\text { of BC (no: 0, } \\
\text { BE: Hosmer } \\
\text { Hosmer and }\end{array}$ \\
\hline
\end{tabular}

\section{Discussion}

In the present study, we determined that the rates for women performing BSE, having CBE, and undergoing mammography were approximately $12 \%, 9 \%$, and $11 \%$, respectively. It was reported in the literature that the rates for women performing BSE, having CBE, and undergoing mammography in developing countries range from $17 \%$ to $50 \%$, from $20 \%$ to $47 \%$, and from $20 \%$ to $55 \%$, respectively [30-35]. In studies carried out at a local level in Turkey, the rates for women performing BSE, having CBE, and undergoing mammography were reported to range from $13 \%$ to $49 \%$, from $15 \%$ to $36 \%$, and from $20 \%$ to $38 \%$, respectively [10-14,36,37]. In the present study, we studied the monthly $\mathrm{BSE}$, annual CBE, and biannual mammography rates in line with the recommendation of the Turkish Ministry of Health, and found that BSE, CBE, and mammography rates were lower than those in other studies carried out in Turkey and other developing countries [2,10-14,36-38]. This difference may be due to differences in the methods used to investigate $\mathrm{BC}$ screening behaviors and from the differences between the participants' age groups in these studies [12-15,30,31,33].

In this study, we determined that the most significant relationships were between health beliefs and BSE (in the last month), CBE (in the last year), and mammography (in the last two years), after adjusting for age, educational level, family history, and perceived economic status among adults. In the present study, women who performed BSE had a higher perception of their susceptibility $[39,40]$ and of their self-efficacy $[10,18,26,27]$, which reflected two of the subscales of the Champion's Health Belief Model. This is consistent with the results in the literature. Susceptibility is a person's beliefs regarding the possibility of facing a health threat. Self-efficacy is defined as "a person's belief that he/she has the competence, determination, and commitment to perform the actions needed to achieve a desired result" $[16,40,41]$. In this context, it can be said that a woman's belief in the possibility of her developing $\mathrm{BC}$ and in her ability to take action against the possibility of developing $\mathrm{BC}$ are strong determinants in the acquisition of cancer prevention behaviors.

In this study, we found that the women who had a high perception of seriousness underwent CBE and mammography more frequently. The concept of perceived seriousness is defined as "a person's beliefs about the severity of the disease". Perceived seriousness includes the assessment of the possible consequences of the illness, such as death, disability, pain, and social losses [21,40]. Studies have indicated that women who perceive the seriousness of $\mathrm{BC}$, and who consider that they are at risk 
of developing BC, tend to undergo CBE and mammography more frequently [30,42]. In this study, we also found that women whose health motivation was high had CBE more often, where health motivation is defined by "their willingness to display a behavior to protect their health". This result is consistent with other results in the literature [30,43]. These results are consistent with the theoretical structure of the Health Belief Model and can be interpreted as follows: the perception of seriousness increases motivation and encourages women to display positive health behaviors, such as undergoing CBE and mammography.

The perceived benefit is the extent to which the person perceives the change in behavior as beneficial and the extent to which he/she believes he/she can prevent the risk of illness if he/she makes the required behavioral change $[21,44]$. The literature shows that high levels of perceived benefits regarding BC contribute to an early diagnosis of the disease and that this increases treatment possibilities, a reduction in cancer-related mortality, prolonged survival, and increased quality of life [45]. In the present study, the BSE and mammography benefit perception was high in women who performed BSE and underwent mammography. The literature states that there is a positive association between perceived benefits, the performing of BSE, and the undergoing of mammography $[10,26,31]$.

On the other hand, this study found that the likelihood of performing BSE and undergoing mammography decreased in women whose perceptions of the barriers to BSE and mammography were high. A perceived barrier is the perception of factors that impede a health-related protective behavior or that make it difficult to display such a behavior [21,40]. These results were consistent with the literature $[18,19,45,46]$, and it can be said that a high perception of the benefit and a low perception of the barriers play important roles in the regular achievement of screening behaviors.

In this study, three screening behaviors for the early diagnosis of BC were evaluated and the evaluation of whether these screening behaviors are performed at the recommended frequencies is one of the strengths of the study; however, this study has some limitations. One of these limitations is that the study had a cross-sectional nature and thus the causal relationship was not displayed. Other limitations of the study were that the questioning of the participants' BC screening behaviors was based on self-reporting, that the study was conducted with women who presented to only one FHC, and that the results could not be generalized to the wider society. Another limitation was that because the current version of the Champion's Health Belief Model Scale [47] was not adapted to Turkish, an older version had to be used.

\section{Conclusions}

In this study, the rates for participants performing BSE, undertaking CBE, and undergoing mammography ranged between $9 \%$ and $12 \%$. Given that the participants in the present study group consisted of women aged 40 and over, who are in an at-risk group for BC, it can be said that these rates were remarkably low. Positive attitudes toward perceived susceptibility, seriousness, self-efficacy, benefits, and health motivation have strong associations with screening behaviors.

In the literature, it is stated that the most important barrier in developing a behavior is the perception of a barrier, and that this perception can be changed by education, counseling, and attempts aimed at increasing access to health services, and thus, as the perception of a barrier decreases, benefit perception increases [19]. In the present study, the perception of a barrier was related to both performing BSE and undergoing mammography.

Health professionals working in primary healthcare institutions should aim to increase women's knowledge and awareness of breast cancer and screening methods, inform them about the national breast cancer screening program, and encourage them to benefit from it. Women should be encouraged to perform and improve their BSE skills. In a future study, focus groups or in-depth interviews should be conducted to reveal the causes of the perception of barriers towards performing BSE and undergoing mammography, and appropriate initiatives should be planned to eliminate the causes identified. Education and consultancy programs that focus on increasing motivation, susceptibility, seriousness, and understanding of the benefits of screening behaviors while eliminating barriers should 
be organized by primary healthcare institutions. To assess BC screening behaviors and investigate their relationship between BC screening behaviors and health beliefs in women, community-based studies should be conducted. In future studies, we should not only investigate factors related to health beliefs but also investigate psychosocial factors and factors related to the use of health services that may be associated with screening. We suggest that BC screening behaviors should be evaluated, not based on self-reporting, but instead based on the records of health institutions.

Author Contributions: Conceptualization, K.T.S. and D.A.; methodology, K.T.S.; formal analysis, K.T.S. and D.A.; investigation, K.T.S., D.A., and G.Y.D.; resources, K.T.S.; data curation, D.A.; writing-original draft preparation, K.T.S., D.A., G.Y.D., and Y.M.; writing—review and editing, K.T.S., D.A., G.Y.D., and Y.M.; visualization, K.T.S. and D.A.; supervision, K.T.S. All authors have seen and approved the final version of the paper. All authors have read and agreed to the published version of the manuscript.

Funding: This research received no external funding.

Conflicts of Interest: The authors declare no conflict of interest.

\section{References}

1. Bray, F.; Ferlay, J.; Soerjomataram, I.; Siegel, R.L.; Torre, L.A.; Jemal, A. Global cancer statistics 2018: GLOBOCAN estimates of incidence and mortality worldwide for 36 cancers in 185 countries. CA Cancer J. Clin. 2018, 68, 394-424. [CrossRef] [PubMed]

2. TR Ministry of Health. Turkey Cancer Control Programme 2013-2018; TR Ministry of Health: Ankara, Turkey, 2016.

3. Chaka, E.E. Breast cancer incidence, mortality and its risk factors among women worldwide. J. Health Med. Nurs. 2015, 16, 59-66.

4. Rivera-Franco, M.M.; Leon-Rodriguez, E. Delays in breast cancer detection and treatment in developing countries. Breast Cancer Basic. Clin. Res. 2018, 12, 1-5. [CrossRef] [PubMed]

5. TR Ministry of Health. Breast Cancer Screening Program National Standards. Available online: https://hsgm.saglik.gov.tr/tr/kanser-tarama-standartlari/listesi/meme-kanseri-tarama-program\% C4\%B1-ulusal-standartlar\%C4\%B1.html (accessed on 11 June 2020).

6. TR Ministry of Health. Cancer Screening. Available online: https://hsgm.saglik.gov.tr/tr/kanser-taramalari (accessed on 11 June 2020).

7. Bingöl, D.; Kılıcıkesen, E.; Aydemir, C.; Duman, N.B. Current approaches in breast cancer screening for elderly women. Turk. Clin. Obstet.-Women's Health Dis. Nurs.-Spec. Top. 2019, 5, 15-18.

8. World Health Organization (WHO). Breast Cancer: Prevention and Control. Available online: https: //www.who.int/cancer/detection/breastcancer/en/index3.html (accessed on 11 June 2020).

9. Kösters, J.P.; Gøtzsche, P.C. Regular self-examination or clinical examination for early detection of breast cancer. Cochrane Dat. Syst. Rev. 2003, 2, CD003373. [CrossRef] [PubMed]

10. Çevik, C.; Güneş, S.; Hattatoğlu, D.T.; Satıcı, M.A.; Bulut, B.; Şahin, S.C.; Kocataş, M.; Çıflik, L.; Kaygusuz, S.; Eser, E. Knowledge, attitude and behaviors of women between the ages of 40-69 on early detection of breast cancer. TJFMPC 2019, 13, 119-128. [CrossRef]

11. Korkut, Y. Assessment of knowledge, attitudes, and behaviors regarding breast and cervical cancer among women in western Turkey. J. Int. Med. Res. 2019, 47, 1660-1666. [CrossRef]

12. Ertem, G.; Donmez, Y.C.; Dolgun, E. Determination of the health belief and attitude of women regarding breast cancer and breast self-exam. J. Breast Health 2017, 13, 62-66. [CrossRef]

13. Hocaoglu, M.; Ersahin, A.A.; Akdeniz, E. Evaluation on the practice and behaviour of women applied for gynecology outpatient clinics about screening methods for early diagnosis of breast cancer. Eur. J. Breast Health 2017, 13, 150-155. [CrossRef] [PubMed]

14. Sozmen, K.; Unal, B.; Sakarya, S.; Dinç, G.; Yardım, N.; Keskinkılıç, B.; Ergör, G. Determinants of breast and cervical cancer screening uptake among women in Turkey. Asia Pac. J. Public Health 2016, 26, 528-538. [CrossRef]

15. Aker, S.; Oz, H.; Tuncel, E.K. Practice of breast cancer early diagnosis methods among women living in Samsun, and factors associated with this practice. J. Breast Health 2015, 11, 115-122. [CrossRef] [PubMed] 
16. Darvishpour, A.; Vajari, S.M.; Noroozi, S. Can health belief model predict breast cancer screening behaviors? J. Med. Sci. 2018, 6, 949-953. [CrossRef] [PubMed]

17. Mousavi, F.; Shojaei, P.; Homasan, S. Health beliefs as predictors of breast self-examination behavior. Int. J. Women Health Wellness 2018, 4, 1-10.

18. VanDyke, S.D.; Shell, M.D. Health beliefs and breast cancer screening in rural appalachia: An evaluation of the health belief model. J. Rural Health 2017, 33, 350-360. [CrossRef] [PubMed]

19. Abolfotouh, M.A.; Bani Mustafa, A.A.; Mahfouz, A.A.; Al-Assiri, M.H.; Al-Juhani, A.F.; Alaskar, A.S. Using the health belief model to predict breast self-examination among Saudi women. BMC Public Health 2015, 15, 1163. [CrossRef] [PubMed]

20. Wu, Z.; Liu, Y.; Li, X.; Li, C.; Lin, F. Factors associated with breast cancer screening participation among women in mainland China: A systematic review. BMJ Open 2019, 9, e028705. [CrossRef]

21. Gozum, S.; Capik, C. A guide in the development of health behaviours: Health belief model (HBM). J. Dokuz Eylul Univ. Nurs. Faculty 2014, 7, 230-237.

22. Ghaffari, M.; Nabavi Rad, T.; Mohammadi, S.; Rakhshanderou, S. Effect of an intervention on the breast cancer screening behavior in women: Application of integrated behavioral model. Int. J. Prev. Med. 2018, 9,99 .

23. Birhane, N.; Mamo, A.; Girma, E.; Asfaw, S. Predictors of breast self-examination among female teachers in Ethiopia using health belief model. Arch. Public Health 2015, 73, 39. [CrossRef]

24. Eltwansy, M.S. Early detection of breast cancer: Knowledge, perception and barriers. EJCM 2018, 36, 11-22.

25. Shiryazdi, S.M.; Kholasehzadeh, G.; Neamatzadeh, H.; Kargar, S. Health beliefs and breast cancer screening behaviors among Iranian female health workers. Asian Pac. J. Cancer Prev. 2014, 15, 9817-9822. [CrossRef] [PubMed]

26. Ü̈çüncü, M.Z.; Üçüncü, M.M.; Toprak, D. Evaluation knowledge, attitude, and behaviour for breast cancer among young women living in two different habitats of Turkey. Asian Pac. J. Cancer Prev. 2018, 19, 3179-3185. [CrossRef] [PubMed]

27. Alvur, T.M.; Çınar, N.; Zengin, H. Health belief model and breast cancer in Sakarya: A cross sectional study. Int. Refereed Acad. J. Sports Health Med. Sci. 2019, 30, 52-67.

28. Center for Disease Control Prevention. Epi Info ${ }^{\mathrm{TM}}$ Downloads. Available online: https://www.cdc.gov/ epiinfo/support/downloads.html (accessed on 12 June 2020).

29. Gozum, S.; Karayurt, O.; Aydin, I. The results of Turkish adaptations of champion's health belief model scale at breast cancer screening. J. Res. Dev. Nurs. 2004, 1, 71-85.

30. Khan, E.; Khalid, A.B.; Anwar, A.; Safeer, N. Knowledge attitude and practice regarding screening of breast cancer among women in Karachi. Online Turk. J. Health Sci. 2019, 4, 301-314.

31. Kwok, C.; Lee, M.J.; Lee, C.F. Breast cancer perceptions and screening behaviors among Korean women in Australia. J. Immigr. Minor Health 2020, 22, 126-133. [CrossRef]

32. Kwok, C.; Endrawes, G.; Lee, C.F. Breast cancer screening beliefs questionnaire: Psychometric properties assessment of the Arabic version. Eur. J. Oncol. Nurs. 2016, 20, 42-48. [CrossRef]

33. Lee, H.Y.; Stange, M.J.; Ahluwalia, J.S. Breast cancer screening behaviors among Korean American immigrant women: Findings from the health belief model. J. Transcult. Nurs. 2015, 26, 450-457. [CrossRef]

34. Othman, A.; Ahram, M.; Al-Tarawneh, M.R.; Shahrouri, M. Knowledge, attitudes and practices of breast cancer screening among women in Jordan. Healthcare Women Int. 2015, 36, 578-592. [CrossRef]

35. Gan, Y.X.; Lao, C.K.; Chan, A. Breast cancer screening behavior, attitude, barriers among middle-aged Chinese women in Macao, China. J. Public Health 2018, 40, e560-e570. [CrossRef]

36. Askin, M.; Koc, E.M.; Arslan, M. Demographic variables affecting women's participation in breast cancer screenings. Med. J. Izmir. Hosp. 2019, 23, 25-32.

37. Sohbet, R.; Karasu, F. Investigation of the knowledge, behavior and applications of their women towards breast cancer. Gumushane Univ. J. Health Sci. 2017, 6, 113-121.

38. Kim, M.; Kim, H.; Choi, H.; Son, M.; Lee, K.S.; Han, T.H.; Kim, S. Age-standardized breast cancer detection rates of breast cancer screening program by age group in Korea: Comparison with age-standardized incidence rates from the Korea central cancer registry. Healthcare 2020, 8, 132. [CrossRef]

39. Abay, M.; Tuke, G.; Zewdie, E.; Abraha, T.H.; Grum, T.; Brhane, E. Breast self-examination practice and associated factors among women aged 20-70 years attending public health institutions of Adwa town, North Ethiopia. BMC Res. Notes 2018, 11, 622. [CrossRef] [PubMed] 
40. Pirzadeh, A. Application of the health belief model in breast self-examination by Iranian female university students. Int. J. Cancer Manag. 2018, 11, e7706. [CrossRef]

41. Khorsandi, B.; Khakbazan, Z.; Mahmoodzadeh, H.A.; Haghani, H.; Farnam, F.; Damghanian, M. Self-efficacy of the first-degree relatives of patients with breast cancer in the prevention of cancer: Using the Health Belief Model. J. Cancer Edu. 2019. [CrossRef]

42. Lee, E.E.; Nandy, K.; Szalacha, L.; Park, H.; Oh, K.M.; Lee, J.; Menon, U. Korean American women and mammogram uptake. J. Immigr. Minor. Health 2016, 18, 179-186. [CrossRef] [PubMed]

43. Tuzcu, A.; Bahar, Z.; Gözüm, S. Effects of interventions based on health behavior models on breast cancer screening behaviors of migrant women in Turkey. Cancer Nurs. 2016, 39, E40-E50. [CrossRef]

44. Chin, J.H.; Mansori, S. Theory of planned behaviour and health belief model: Females' intention on breast cancer screening. Cogent Psychol. 2019, 6, 1647927. [CrossRef]

45. Noori, S.; Schouten, B.C. Perceptions of Iranian women regarding breast cancer screening behaviour. East Mediterr. Health J. 2019, 24, 1165-1171. [CrossRef]

46. Roh, S.; Burnette, C.E.; Lee, Y.S.; Jun, J.S.; Lee, H.Y.; Lee, K.H. Breast cancer literacy and health beliefs related to breast cancer screening among American Indian women. Soc. Work Health Care 2018, 57, 465-482. [CrossRef] [PubMed]

47. Dewi, T.K. Validation of the Indonesian version of Champion's Health Belief Model Scale for breast self-examination. Psychol. Res. Behav. Manag. 2018, 11, 433-438. [CrossRef] [PubMed]

(C) 2020 by the authors. Licensee MDPI, Basel, Switzerland. This article is an open access article distributed under the terms and conditions of the Creative Commons Attribution (CC BY) license (http://creativecommons.org/licenses/by/4.0/). 